Article

\title{
The "Local Town Market Area" in Enna, Sicily: Using the Psychology of Sustainability to Propose Sustainable and Developmental Policies
}

\author{
Romina Fucà $^{1, *}$, Serena Cubico ${ }^{2, *(\mathbb{D}}$, Giuseppe Favretto ${ }^{2}$ (D) and João Leitão $^{3,4}(\mathbb{D}$ \\ 1 Department of Law, University of Macerata, I-62100 Macerata, Italy \\ 2 Department of Business Administration, University of Verona, I-37129 Verona, Italy; \\ giuseppe.favretto@univr.it \\ 3 Department of Management and Economics, NECE, University of Beira Interior, PT-6200-209 Covilhã, \\ Portugal; jleitao@ubi.pt \\ 4 The Centre for Management Studies of Instituto Superior Técnico (CEG-IST), University of Lisbon, \\ 1649-004 Lisbon, Portugal \\ * Correspondence: romina.fuca@hotmail.it (R.F.); serena.cubico@univr.it (S.C.); Tel.: +39-333-3379170 (R.F.); \\ $+39-045-8028132$ (S.C.)
}

Received: 29 December 2018; Accepted: 11 January 2019; Published: 17 January 2019

\begin{abstract}
Ritualization operated by analyzing macro-sectors in a city (e.g., neighborhoods) has concluded irreversibly for condemning some dilapidated areas instead of others. Taking its cue from the scenario of the 17 Sustainable Development Goals, particularly Goal 11-Make cities inclusive, safe, resilient and sustainable (United Nations) - the realized analysis links a sustainable urban design with the citizens' role in the city in a particular urban landmark, the "local town market area" (LTMA), with a focus on developing the well-being of the local community, also referred to as the psychology of sustainability and sustainable development. Principal methods of inquiry used, along a geospatial Google-driven investigation, were self-observation and self-assessment, which reflect both the study of self-organizing systems in the context of complexity and systemic theory, choosing to detect the spatial state of a specific area, as it has neither official nor institutional boundaries. The approach to crime prevention through environmental design (CPTED) is therefore discussed through the maximizing of the LTMA functional urban unit in Enna, Sicily, to reach the idea of a community that is innovative and participatory.
\end{abstract}

Keywords: sustainable urban environment; psychology of sustainability and sustainable development; systems theory; self-organizing systems; spatial crime attractors and detractors; geospatial investigation Google-driven; areas with no institutional boundaries; quadrant counts method

\section{Introduction: Sustainability, Reputation of the Cities, and Image Problems}

The new research area of the psychology of sustainability and sustainable development offers solid hints for dealing with image problems and the reputation of cities. Image problems refer to the reputation of an area considered dangerous, filthy, or unattractive as a dwelling site. This reputation is often at odds with the perception of people who associate their positive representations of the neighborhood with people of similar tastes, the presence of green spaces (in the case of neighborhoods on the periphery), places near the city center (in the case of old neighborhoods near to the city's core), and the neighborhood's history and cultural origin (former working-class settlement, garden city and so on).

Cities of the world are the ground on which multiple processes of globalization take concrete and localized forms. These localized forms are, to a large extent, related to globalization. If we also consider 
that large cities are also concentrating a growing share of disadvantaged populations-immigrants both in Europe and in the United States, African Americans and Latin Americans in the United States, and masses of slum dwellers in the megacities of the developed world-we can see that cities have become a strategic terrain for a whole series of conflicts and contradictions [1-3].

Focusing on the threat to urban public spaces and on urban anxiety, as well as working closely with municipal policies, has been found to be useful in counteracting crime. These political issues have now become central [4] (pp. 131-137). In light of the changes over time to planning and administration functions, various causes of fears are expressed by psychologists, social psychologists, media analysts, and cultural theorists, providing an overview of the phenomenon of fear in relation to the city's environment and make-up. Planners and designers do not normally have the opportunity to create plans and designs that may have a direct impact on reducing crime in a particular environment. In fact, even if they could influence such a situation through comprehensive planning and design principles in the physical environment, they still cannot forecast which new parameters and populations (i.e., the "non-regular" and "non-consistent" patterns as inversely predicated by Shaw and McKay (1942)) the built environment could produce and have in the future [5] (pp. 89-97). Therefore, as in the mainstream studies on cities' wellbeing and security concerns, we have also searched for thresholds of city hotspots to set initial classes to identify which relatively high risk areas seem more logical for defining the prevalence of crime and whether the quality of the natural and built environments, including the influence of peers and social networks and the proximity to jobs and resources, could act in favor or against the wellbeing of individuals [6-8]. Because our view is different both temporarily and spatially from the Chicago School, we first of all explain that, in the context of Sicily, "non-consistent" patterns are usual due to the succeeded dominations changing the Sicilian urban environment over centuries. Therefore, it is still important in Sicily to use planning and design to promote territoriality and a "sense of ownership," to maximize opportunity for surveillance, control access, and support activities, and finally to tighten security measures via technological advancements.

We can also consider cities as one of the sites of the contradictions of the globalization of capital. On the one hand, they concentrate a disproportionate share of corporate power and are among the key sites for the hyper valuation of their economy. On the other hand, they concentrate a disproportionate share of disadvantaged people and constitute one of the key sites of their devaluation [9] (pp. 209-210). This common presence occurs in a context in which (1) the transnationalization of economies has grown strongly and cities have become increasingly strategic to global capital, and (2) marginalized people have found their voices and accuse the city [10]. These joint presences turned cities into a disputed land. The city concentrates diversity. Its spaces are part of not only the dominant corporate culture but also the multiplicity of other cultures and identities, including those through immigration. "The shift is obvious: the dominant culture can encompass only part of the city" [9].

Over the last twenty years, regional development and urban revitalization strategies have traditionally been economy-centered: economic strategies have made regions and cities more market-friendly and competitive, physical renewal strategies have strengthened the economic base of the territories, and institutional transformations have focused on creating flexible, investment-friendly, business-friendly environments. However, places and their economies can be viewed more socially, as a set of relationships and practices ranging from everyday family and community life to norms of consumption, to the social regulation of work habits, and to professional practices. The concept of sustainability then offers an alternative perspective on territorial development and transformation, which promotes innovation in social relations [11] (pp. 4-5).

Added to this are security concerns and urgent measures to stop crime. They range from the most lethal cases, especially terrorism, to criminal cartels and gangs that challenge the city's authorities and to socially destructive urban slovenliness [12-14].

As is well explained by S. Sassen (2005), a city is not a circumscribed urban environment, but a complex structure capable of articulating various cross-border processes and reconstructing them as a partially urban condition. Moreover, this type of city cannot simply be placed in a scalar hierarchy 
that places it below national, regional, and global levels. It is one of the world's spaces, and directly engages the world, often bypassing the national surrounding. "Some cities may have had this capacity long before the current era, but today these conditions have been multiplied and amplified to the point that they can be read as contributing to a qualitatively different urban era" [15] (p. 459).

This urban background has also involved for us the analysis of complex processes into their component individual actions, which has in turn singled out techniques for special emphasis and usually neglected other characteristics of actions. Such an example "space syntax research" [16] tends to cluster property crime in segregated areas; in particular, arguing that it might prove appropriate to aggregate locations with low accessibility into areas essentially similar in kind. Similarly, "safe" locations serve as magnets to ordinary citizens who may then act to discourage the presence of criminals [17]; as a contra-effect, although increased numbers of pedestrians may provide additional "eyes on the street," in Jane Jacobs's [18] words, and therefore potentially discourage some offences, but may also actually encourage and provide other targets for crime (e.g., pickpocketing).

Very often, to address territoriality issues in public safety, urban planners have to deal with the demolition of "crack houses," use barriers to cut off traffic from highways, sponsor community clean-up events, and co-ordinate services with immigration issues. It is also necessary to gain knowledge on how people evaluate information in their opinion-making process (this corresponds to concepts in planning theory, which focused on planning as a "communication structure") [19-21].

The application of "exceptional" procedures (that is, those who use routes other than those of the established law), as in the case of the CPTED, the Crime Prevention Through Environmental Design, strengthens locations' stigmas and the feeling of creating a territorial and social divide. Qualitative interview data suggest, however, that residents often do not internalize or resign to the stigma. They become sad or angry when confronted with the stigma, but they have an either positive or ambivalent view over the area and most of them are content to live there [22].

The CPTED's central findings are that the enhancement of elements that reduce crime [23] (pp. 1-214) and other general attempts to obsessively manage the cities' natural spaces have often become boomerangs. For example, Miethe reports the case of Bethesda, in Maryland, U.S.A., which had been ranked in 2008 by Fortune Small Business Magazine as the fifth-best place in the United States "to live and launch." Because of differences in the dimensions and indicators used to establish the rankings, another magazine ranked the same U.S. city in the same year as the 104th [24] (p. 5). The CPTED's failure in the enhancement of cities' sustainability was also observable in the case of the spatial dislocation of the poor, which often resulted in long and costly commuting patterns that in turn left commuters vulnerable to victimization. In fact, the separation of communities through vacant land, railway lines, and other means used especially in the past to divide different groups resulted in the exclusion of many residents from the amenities and economic opportunities offered by the city. Finally, the rigid mono-functional zoning of land, which left some areas deserted at night and others deserted during the day, reduced many residential areas to virtual dormitories. Shapland and Vagg (1988) in a study of an urban area of Britain found the streets deserted of women after dark. As a contra-effect, the constrained behavior in terms of avoidance behavior (avoiding unsafe places and limiting daily activities) and defensive behavior (added security or arming self) was positively related to fear [25] (p. 25).

Always in relation to the reputation of cities, Monteiro and Puttini Iannicelli [26] demonstrated that the perception that places close to poor areas are more unsafe and dangerous is often only an erroneous myth, like in the case of Recife in the northeast of Brazil, known as the most dangerous city in the country. In its district of Boa Viagem, approximately 100,000 residents constitute a highly dense middle-class and upper middle-class area, with new buildings with as many as forty floors. The inefficiency of coercive authorities in addition to there being no clear identification of who the criminals are has made the middle class fortify and isolate themselves behind high walls and non-transparent facades, and install tight security systems with cameras, electric fences, and 
non-transparent gates. The authors attribute the fear in those neighbors, who are used to the logic of the orthogonal city, to the morphology and typology of poor areas.

It is therefore foreseeable, as stressed by prominent scholars, that, at one extreme, the "urban fortress" represents a forced method for providing territoriality where sole dependence is on physical security design. At the other extreme is the "urban village model" [26], which relies solely on cultural or social behavior to establish territoriality. However, communities today, in the words of Ann Power and John Houghton (2007) [27], do not allow for one-size-fits-all interventions. In fact, we can think of global communities as a wide jigsaw, where uniformity is their deepest inequality. As the spatial image of the city is distorted by the waste of its own resources and the shortness of recovery and renewal, its invasion of current building modifications fails to match new conformation of the city. The strategic link is its environmental image: a generalized mental picture of the exterior physical world, which may structure, interpret, and cope with the complex sets of information existing in different environments [28]. The sustainability of space, and other elements unfamiliar to an ordinary observer, in our view must be formlessly "swallowed" at a first stance, because there are more interviews, Google-driven shots, and personal experiences that constitute the imageability of spaces and that can reflect the sense of space of the people living therein.

Because physical arrangements in cities are not ever a natural given and must be constructed through investment strategies oriented-according to our aim - to the psychology of sustainability and sustainable development, also helpful as a reliable source of other benefits, we faced the need to emphasize the central role of a "substrate" location: first, to avoid the trap of presenting community networks and the city's membership as an unwilled occurrence and, second, to keep the analysis within the borders of a socio-psychological analysis rather than that of an idealistic statement. In addition to the difficulty of being encapsulated in common methods of enquiry, cities are affected today by a sharp deterioration in their macroeconomic covenants, which has had a significant impact on social housing and its occupants. Due to successive waves of higher rates of unemployment and closures of many businesses, portions of land that sat vacant for years and have been occupied by people in increasingly precarious conditions, municipalities, and local authorities have entered into crisis (lack of fiscal resources), and public services have irreversibly deteriorated.

Certainly, the territory offers a structural texture, for natural and historical reasons, to which some norms apply better than others. A "norm" plan, especially in the urban context, must be able to define a set of rules more or less durable over time. It must also be compatible with the targets to be matched, so that its focal duty is the effective construction of the necessary strategies to reach suitable targets. Local social ties appear, and they feed into territorial functioning for several reasons. In the literature, territorial functioning is viewed not as a solipsistic or individual-centric system, but rather as a permeable, group-influenced system [29] (pp. 603-651). Another aspect of the relationship between the built environment and security concerns is, in fact, the relationship between "physical disorder" and crime. James Wilson's and George Kelling's "broken windows" hypothesis suggested that physical disorder could act as a signal to criminals about the lack of social investment in a community and could lead to increased crime [30] (pp. 29-38).

In its origins, the Greek word "polis" meant the "headquarters" of a city (generally in an upside location). Thereinafter, since the eighth century, the term started to indicate building developments of an urban or better pre-urban feature. These developments were mainly protected from the headquarters but could also be self-defense places, both enjoying a natural favorable morphology, and reinforcement systems (e.g., fortifications). Since then, many of these communities have become autonomous urban unities, the term "polis" upheld in its classical meaning [31] (p. 9).

Autonomy of urban settlements was therefore portrayed, firstly, by a natural aspect (its morphology) and, secondly, by a manipulated structure organization (its urban design). Only at the starting of the eighteenth century, with the industrial revolution and its related polluting sprawl (also of immoral incivilities), were building codes associated directly with human safety [32], in terms of the wellness of citizens, and indirectly with the insecurity sources' containment in the cities. However, the issue had 
already been seriously taken into consideration in the thirteenth Century by The Statute of Winchester of King Edward I (1285), who stated "[ ... ] that the highways from market towns to other market towns be widened where there are woods or hedges or ditches, so that there be no ditch, underwood or bushes where one could hide with evil intent within two hundred feet of the road on one side or the other side... And if perchance there is a park near the highway, it will behoove the lord of the park to reduce his park until there is a verge two hundred foot wide at the side of the highway, as aforesaid, or to make a wall, ditch or hedge that malefactors cannot get over or get back over to do evil." [33] (p. 701).

Bottoms and Wiles (1997) use the term "environmental criminology," which they define as "the study of crime, criminality, and victimization as they relate first to particular places and secondly to the way that individuals and organizations shape their activities spatially and, in so doing, are in turn influenced by place-based or spatial factors" [34] (p. 633). Most targets are selected from within a criminal's awareness space. Property crimes should occur disproportionately in those areas in which criminals carry out their routine patterns of activity [35-38]. Therefore, the environmental opportunity structure influences security concerns' patterns, and this influence stems from both the physical limitations that the built environment imposes on the individual and the cognitive representation (awareness space) that the individual has of the environment. To effect the desired changes, those engaged in public planning need to understand the circumstances and criteria that people employ in arriving at a judgment relating to a security issue. Such individuals are more often liable for resolving contradictions and deep-seated conflicts between, on the one hand, competing interests over the use and development of land and, on the other, community interests over property rights. The urban planning system has already been defined as "overburdened" in its role [39] (p. 561).

For example, the neighborhood ZEN, in Palermo, Sicily, is emblematic not only of the disqualification that affected large groups but also of remedies that have been applied to them since the late 1990s. Its incompleteness led to a strong densification: $64 \%$ of housing as programmed initially had to be managed by local authorities; $35 \%$ of buildings were divided into seven sub-districts with a total area of 3700 hectares, but all processes were arrested by repeated demolitions during the construction of ZEN2. After a relatively quiet period, this nurtured a vibrant community life of mingling workers and middle-class individuals. The ZEN entered into a difficult phase. It suffered from a combination of economical crisis and the decline of industrial activities in the region in the late 1980s, the acute awareness of the distance from the center of the true city and the fall in the attractiveness of abstract models of urban planning in a large crowd of individual poor housing. The negative perception of the ZEN since then has grown rapidly and led to the hasty escape of the middle class at the arrival of a poor population, largely drawn from immigration and increasingly weakened by limited employment opportunities. Qualitative interview data suggest, however, that the residents do not internalize or resign themselves to the stigma. They become sad or angry when confronted with the stigma, but they have an either positive or ambivalent view of the area. Most of them are content to live there [40] (p. 249).

\section{A Short Historical Summary to Retrace the Beginnings of Urbanization in Sicily}

In Sicily, it is possible to appreciate the broad patterns of land use (precincts and quarters), patterns of sub-divisions of blocks (typical frontage dimensions and depth of block), the distribution and amounts of land uses (residential, commercial, retail, community and employment) at street level and upper floors, the social mix (private and social housing), ownership, and tenure. The judgment of being far from the "global" character of Sicily can be interpreted as an indication of the dominance of Arabic influences on the towns before the modern era [41] (p. 22). In the modern era, the prevailing system of land use regulation-precluding the diversity of uses-established the location of slaughter houses, fisheries, tanneries, and other businesses. Similarly, these laws required the construction of arcades around the central plaza, for these were of considerable convenience to the merchants who generally gathered there [42] (pp. 31-41). In the 1880s, modern land use regulation began when Sicily 
passed ordinances regulating the location of neighborhoods. By 1920, Sicily was zoned into 200 large residential districts and 50 industrial districts.

The true history of land use regulation in Sicily had begun in the middle-sixteenth century, when the Kings of Spain issued the Laws of the Indies. In 1610, a first crucial legislation from Spain upheld the Sicilian Barons of the right to acquire "pieces of the Spanish Empire" (the so-called licentia populandi or privilegium edificandi). Thus, the urban phenomenon in Sicily presents characteristics of autonomy, where the blending between confining territories does not respect strictly the administrative boundaries, and the political design is influenced by some casual factors. The most widespread circumstance is that all the areas where there was a new inhabited center were particularly suited to cereal crops. Even the altitude had its importance. The municipalities born during protofeudalism were generally located on impervious heights, at altitudes above 400-500 m; the newly founded municipalities, on the other hand, were located in the hills or in the plains [42] (pp. 44-45). The birth of new rural agglomerations compensates for the need for new agricultural areas to be cultivated. The displacement of the population from the old to the new municipalities was then a process of demographic osmosis. "The displacement of the population from the old to the new municipalities was a process of demographic osmosis between neighboring territories" [42] (p. 47). In light of the assets of the church mortmain, not owing any leading groups to the existing homogeneous municipalities, the only social class that could have interest in the colonization of the island was the baronage. From this point of view, the privileges and titles that the Spanish royal administration recognized to all those who promoted the founding of a new municipality should be considered a drive for the economical growth of Barons who otherwise would have lived solely through bills, taxes, and noble privileges [42] (pp. 49-50).

In fact, overarching benefits would have led the population's transfer from the old settlements toward the new ones, but prerequisites to obtain the licentia populandi to determine the ground lease ratio were many: the availability of drinkable water for humans and animals, the presence of healthy air, the proximity of quarries to obtain building materials, and the accessibility to major thoroughfares of the time. As a disadvantage, this situation did not produce any great commercial or industrial city, an outcome that at a later time economic dualism will symbolize as a haunting difference between the north and the south of Italy.

An explosive growth of urban settlements had then occurred between the sixteenth and eighteenth centuries, as witnessed by the two official censuses in 1583 and in 1714, respectively. In 1583, the population density in the island was very low, about 31 inhabitants per square kilometer, with an average mean of 4000 people per Sicilian town. Until the feudal period (officially ending in 1812), population in the towns decreased slowly because more settlements were growing and were scattered in more inaccessible areas. In fact, the main actors entitled to Sicilian urbanization had been the feudal Barons and they were keen to build little towns with all the characteristics of a feudal village, such as castles, towers, and walls to protect their properties.

During its transformation toward the end of feudal sovereignty, Sicily enjoyed very large settlements with a true urban center augmented by the so-called "common lands"; they were, by land, allowed to be commercialized and, by feudal properties, co-shared by the noblesse, the church, and the university. The administrative subdivisions were by "districts" (so-called comarche) from 1583 until 1812; in 1812, following the collapse of the feudal system, 23 "districts" were recognized. In addition, these schematic historical traits suggest how cities in Sicily, since their foundation, did not retain effective jurisdictional and political control over their land because rural powers contended the legal ones. New towns in the countryside were in a stronger position than the traditional urban world in the rest of Italy, a fact confirmed by the resiliency that was, during the time of economic depression, more dynamic than in the rest of the country. Towns in Sicily are one of the best examples of operating in accordance with an entrepreneurial logic where the founder granted the least possible to their own inhabitants, with the aim at gaining the maximum profit with the minimum risk. Moreover, on a smaller scale with respect to its connection with the great European culture of the epoch, the Sicilian 
urban culture detaches itself from the formal reorganization of the territory around a castle-which continues to be experienced in other parts of Italy-and gives its vital core to the plaza, the Church, and the baronial palace. This was a "new way to conceive the territory and its natural resources, whose orthogonal plant is an outcome perfectly correspondent to its scope" [42] (p. 59).

\section{A Main Theoretical Question: Is Sicily Then Truly a Mirror of Europe?}

Through the inclusion of an overall historical background, we heighten the need to be aware of the land of Sicily and to understand how much we adhere to safeguarding the quality of our actual living standards. Therefore, we asked ourselves if we actually grasp the true meaning of preservation and sustainability of our land, in light also of a major trend now in the whole of Europe and elsewhere $[43,44]$. First, what kinds of problems are encountered in urban planning research as a result of the lack of a systematic training of researchers and experts in urban systems? Second, the institutional basis for further research in urban planning is different. In some countries, many institutions have established offices that are responsible for urban development and/or improvements in planning and design, their staff are often involved in research as well as with students' teaching.

This informs us, especially in Europe, of the necessity to unfasten an exchange of ideas with the "material transformations" [45] (pp. 52-53) of cities, that is to understand the urban condition as the prevailing model of the social organization today and an incentive to see planners as the true interpreters of the past and current historical processes.

The European spatial development perspective has made reference to this point, cautioning that "... spatial development policies must not standardize local and regional identities in the EU, which help enrich the quality of life of its citizens" [46] (p. 7). Today, in addition to the difficulty to encapsulate the European urban patterns worldwide, cities are affected by a sharp deterioration in their macro-economic covenants, which has had a significant impact on social housing and its occupants. Because of successive waves of higher rates of unemployment and closures of many businesses, portions of land that have sat vacant for years and have been occupied by people in increasingly precarious conditions, municipalities, and local authorities have entered into crisis (lack of fiscal resources), and very often public services have irreversibly deteriorated.

At the other extreme, larger cities in Sicily have made up a small segment of all cities, but their share of the total urban population has grown. As of 2012, four metro areas having less than 1 million inhabitants (Palermo, Trapani, Catania, and Messina) accounted for $53 \%$ of the total urban population in Sicily. At a macro level of analysis, we therefore have to deal with the system of towns in Sicily. If cultures are something more than fortuitous agglomerations of traits, if borrowing involves selection and re-adaptation, if cultural change is an adaptive process, then even historically connected cultures become, in a very real sense, independent units. The question is how do we cluster all of these units in an efficient way to achieve the aim of our analysis?

\section{The Taxonomical Globality of Cities and the Search for a New Area Unit of Enquiry in Enna, Sicily}

Already anticipated in our introduction, the "global city," in the formulation of Saskia Sassen [47], is now a popular concept with the aim of understanding urban modifications in the context of both cultural and economic globalization. Its main message can be summarized as follows: the globalization of economy creates a new type of city, the global city, which acts as a reference ground for global economical activities, an interface for global connections, and a control place on global flows.

This is evident in a first recurring confusion between the terms "city," "town," and most recently "suburb." The institutional and organizational aspects of the city have been established since medieval times, the epoch of the vagrants, who in an "open" space conveyed interests, affairs, and identity aggregation. The city also has a proclivity to schematize ambiguities, that is, to mythologize its abstract functions into an ideology of internal and external boundaries that separate it from the world outside of it. Neither a sociological analysis, nor a topographic one, can really explain how the worldwide "city" works today. The digital and the global deeply overlay each other, such that a sociological or 
topographic representation both fail to capture the fact that global power projects located on global circuits destabilize the meaning of the local or the site of a city. As formulated by Saskia Sassen [47] (p. 13), "key concepts in the dominant account about the global economy-globalization, information economy, and telematics-all suggest that place no longer matters. They suggest that the type of place represented by major cities may have become obsolete from the perspective of the economy, particularly for the leading industries, as these have the best access to, and are the most advanced users of, telematics."

This economical and geographical categorization has some social outcomes, as it were, for the city: it must be endowed with a high concentration of standard facilities with a spatial fragmentation and a social polarization. The city then becomes "double"; on the one hand, a small world of successful globally tied businesses (e.g., McDonald's, Sony, Apple, Disney, and other leisure and cultural industries) and, on the other hand, an increasing bundle of new categories of poor people segregated from the rest of the world (e.g., dwellers in the favelas, inhabitants in underdeveloped peripheries, and so on). The main methodological question arisen from our research is illustrated in Figure 1.

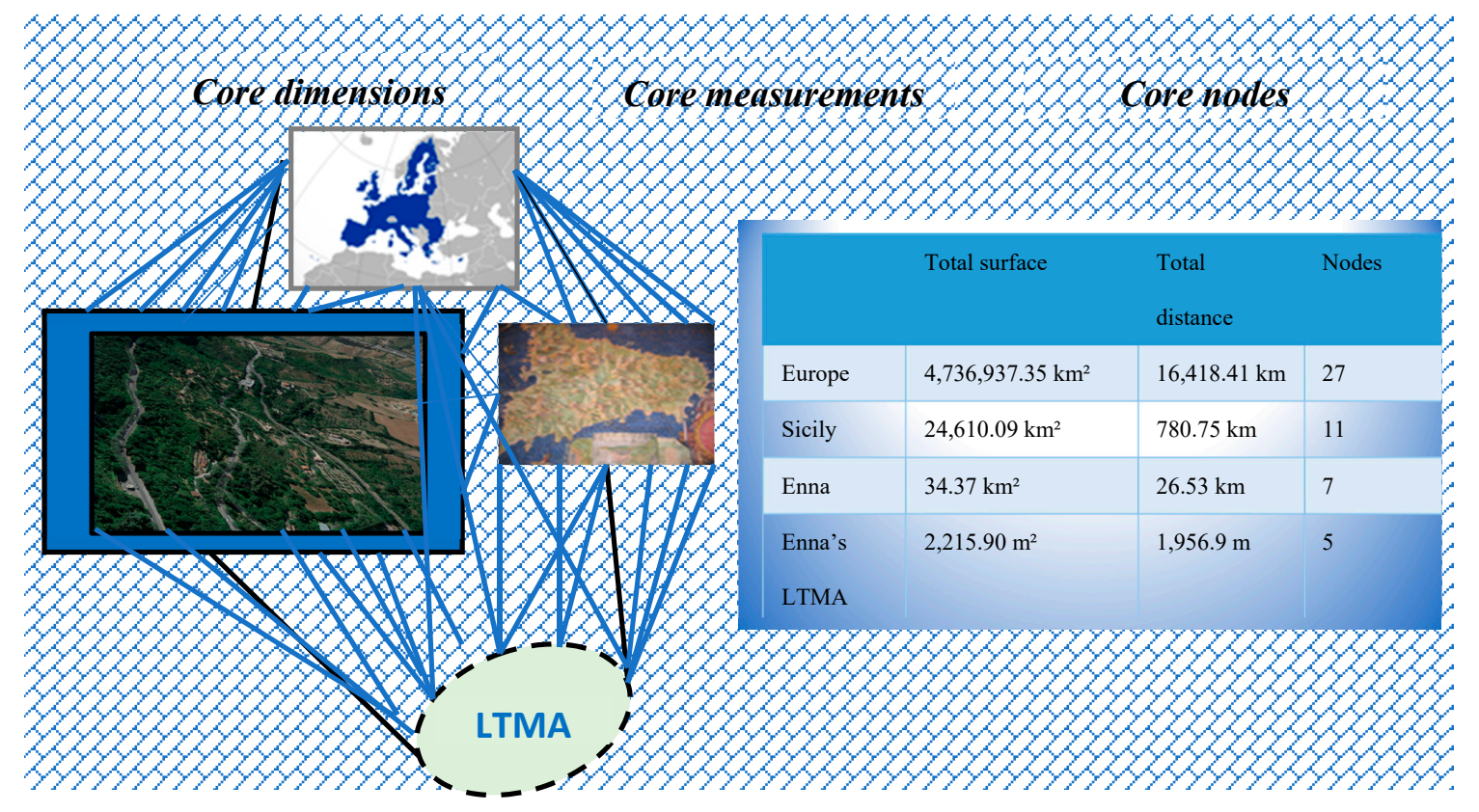

Figure 1. The theoretical question arisen from the research. Top center: Europe. On the left an edge periphery of Enna in Sicily. On the right, a famous drawing of Sicily kept on the Holy See Museum. At the bottom, the LTMA looked after by the authors. In the right table, a look at the total surface of each component of our question.

Planners generally (1) give priority to the development of a territory or to the allotment and renovation of a neighborhood that has encountered factual distinctions thanks to the simultaneous effect of the de-industrialization and the building of periphery thoroughfare infrastructures, (2) enhance the diversification of the habitat and its consequent mixing of functions/equipment/activities, (3) provide the restoration of the social equilibrium and its related improvement toward populations that experience dilapidation, or (4) define the valorization of the suburbs' cultural identity [48] (pp. 2-3).

Taxonomy has developed in recent years with a conversion of European regional units into functional units, where the attention is mainly given to the job activities' index of an urban area. Note that this kind of urban configuration is not restricted to the incorporation of territories and near locations, nor to the widening of viability or to the diversification of structural axes. The contradiction is related to encompassing activities (industrial, cultural, and political), investments, and people in the urban nuclei, which are relevant but neatly differentiated by a personal structural independence 
and, though tightly integrated in functional terms and/or tied up by material and symbolic flows, are essential but not necessary to the majority of the inhabitants. The self-assessment, ideally, could reflect a subtle balance between qualitative and quantitative data. However, there is no doubt that the quantitative side, often bordering on performance indicators, can cause some apprehension. Many cities are not yet ready to compile and distribute specific data records.

A typology of Sicilian public spaces, based on criteria focusing on local markets and describing the internal fabric and the connections to the surrounding urban space, has been therefore constructed to the aims of our investigation. This way, "local town market areas" (LTMAs) have been presented, on the one hand, as typical examples, mostly taken from classical Arabic markets typology; on the other hand, as theoretical sketches making up a set of models of reference available for contemporary projects of crime prevention. Our shared conviction is that the high density, diversity, and proximity of facilities in LTMAs can offer a good sustainable urban model, especially when spatial factors are balanced with their users' or inhabitants' acknowledged ability. The ad hoc urban community of the local market, characterized by a higher spatial cognition of residents and smoother cultural/regional differences because of the essential motivation of economical exchange, creates feelings of self-security and offers a significant social and spatial survey area. The original urban fabric has therefore been studied as the true joining between environmental and urban features, on the one hand, and social dynamics, on the other. The salience of types moved from traditional patterns of development in the studied Sicilian urban contexts have revealed a special organizational form, where the local market assumes the role of cell elements for territoriality, monitoring, and self-security feelings.

In Sicily, the urban system is still dominated by small towns. Indeed, the extension of the urban perimeter of most major cities is accompanied by an increase in small- and medium-sized cities, urban districts of 20,000-60,000 people, representing over $60 \%$ of the cities. Small towns are therefore increasingly fulfilling functions through the development of service activities in administration, education, and health. Through decentralization and the downward migration of officials and executives, they have acquired functions of administrative, shopping, and even manufacturing centers.

The present aim includes the recognition of a field of activity, an LTMA, which is centered on how component parts operate. Although both in Enna and Agrigento towns undoubtedly play a special role in Sicily—as the provider of tourist services, hand-worked pottery shops, and local administrative centers-the local town markets function as retailers of foodstuffs, and other goods that differentiate between the "urban" and "rural" economies make no sense at all. Its social structure is then analyzed, highlighting both the fluidity of the town's society (a fluidity which helps to unify the town with its surrounding area) and the effective division of the society into two parts: a classical model of a town and a model related to LTMAs seen as a self-organizing system in which elements are designed to dynamically and autonomously solve problems including demarcation that could be suitable to perform a function at the level of self-security. Existing research generally has identified specific modifications to the built environment that can effectively reduce crime and violence.

Many scholars have argued that design should "create opportunities for natural surveillance by residents, neighbors, and bystanders" [49]. For example, today surveillance is enhanced first by improving street lighting. Clarke [50] found that better lighting can reduce crime, disorder, and fear of crime. Farrington's and Welsh's [51] systematic review and meta-analysis (based on 13 high-quality evaluations from the USA and the UK) found that improved street lighting is effective in city and town centers, residential areas, and public housing communities, especially in reducing property crime as opposed to violent crime. This concept is an extension of Jane Jacobs's [18] influential theory that "eyes upon the street" and general street activity reduces criminal activity. Routine activities theory, which has been featured prominently in criminology literature, stresses the importance of capable guardianship in reducing the propensity of motivated offenders to commit crimes toward susceptible targets. The process by which individuals living in neighborhoods actively intervene in ways that discourage problematic behavior has been termed "collective efficacy" [52] (pp. 10-11). On the other hand, researchers have concluded that contrary to Jane Jacobs's (1961) suggestion, commercial uses are 
associated with increased crime rates. Similarly, considerable research on this issue has shown that homogeneous residential neighborhoods have lower crime rates than mixed-use neighborhoods [33].

For instance, the important message about the potential of people to transform places is expressed well by the retrofitting at the Eldonian Village in Liverpool, which represents a best practice of how to provide a sustainable community approach to a failing neighborhood. According to Roberts [53] (p. 129), "the Eldonian themselves recognize that there is a need to remain vigilant and that there are still many tasks to be undertaken both within the Eldonian Village. Some observers have criticized aspects of the village itself and the Eldonians as an organization. For example, parts of the village are fenced off from the surrounding area, but access to the village is unrestricted and it cannot be described as a gated community."

These characteristics are also broadly in accordance with the fundamental requirements of the sustainable community's approach, where key elements of successful regeneration are included among the most important features: the presence of an overall vision and strategy, the need to establish a broad-based and lasting partnership, the need to build a community capacity to allow empowerment, and the importance of creating a social infrastructure in a neighborhood. The criminal subjective indicators for public safety are due, among others, to the effect that may exercise crime settings on the behavior of people and demonstrate how much crime occurrences affect an individual's quality of life, such as when persons carry out certain behaviors (e.g., outside the home activities) due to their reduced economical power. The sum of such individual practices may eventually lead to a decline of social activities in certain public spaces. In turn, this reduces the effectiveness of informal social control in the public where- by crime and fear of crime-are therefore considered indirect costs of crime $[54,55]$.

The standard indicator, albeit with different formulations and with different answers, is used basically with similar content: "How safe do you feel in your neighborhood if you go out at night alone onto the street?" or "Would you even consider going?" Usually, the cognitive dimension is measured by assessing a person's likelihood of becoming a victim of a particular offense in the next twelve months. The risk assessment is, however, not to be construed as an alternative to an affective fear of crime. Rather, affective crimes are a function of the risk assessment; that is, the fear of crime and risk are in very close (causal) connection.

The CPTED requires communities whose property owners and residents know one another and recognize outsiders. Streets, plots, and homes in a neighborhood are laid out so that it is possible to distinguish between public and private property. Windows, lighting, and landscaping allow observation both onto and from individual places. When a neighborhood is arranged in this manner, local residents are comfortable in questioning and reporting unusual behavior [56] (pp. 22-27). This is the "defensible space" in the words of US architect, Oscar Newman [23], issued from the search for identity of both public and private spaces.

Often, assessment services (whether statistical offices or specialized study centers in other countries) do not give the impression that a true technical approach has been adopted. For example, traffic flows are not the only component to take into account, but they are an important factor. We can say that a traffic flow's deviation will be more efficient if, for a given LTMA density, it increases the average speeds of vehicles. On the other hand, it will be more efficient when the population having access to the LTMA will be higher and more affluent. This can trigger some puzzling questions by traffic officials who want to create a safer area, while accounting at the same time for more bargaining presence amid the stalls selling hardware supplies, shoes, clothes, cooking supplies, pharmaceutical supplies, and so on.

\section{Discussion: How Is an LTMA Determined?}

The first issue in the selected case study of Enna, Sicily, was to find a spatial scale that could communicate information about the occurrence of crime through modalities, which were independent processes from a demographic orientation. Nothing is too hasty, such as to connect an increase or 
decrease in crime rate to people's ages, ethnic differentiation, income, and/or unemployment rates, among others (see "Introduction: Image Problems and Reputation of the Cities"). The original urban fabric has therefore been studied as the true joining between environmental and urban features, on the one hand, and social dynamics, on the other. Salient features have moved from traditional patterns of development in the enquired Sicilian urban contexts and have revealed a special organizational form, where the local town market assumes the role of cell elements for territoriality, monitoring, and feelings of self-security.

In other words, preference should be given to revitalizations that are appropriately located so as not to undermine the ensemble of an area, including its countryside, which is accessible by sustainable modes of transport. Policies should ensure that existing communities are safe and sustainable places to live; they should bring empty properties back into use, as well as previewing the demolition of housing that is no longer viable or in demand. In doing so, preventing the loss of family homes may be achieved through subdivision, a change in use, or redevelopment and by preventing an over-concentration of shared accommodation.

Though these dimensions can be closely interrelated, their trajectories do not necessarily converge, either in scope or in time. In many city regions, the tendencies of economic and social change have become so dynamic during the process of radical modernization since the early 1990s that planning strategies and institutional conditions are no longer adequate to match the pace of ever-changing parameters. There has to be an end to this variability in the European urban system in view of the classical CPTED approach because neighborhoods and districts in Europe are not as free-formed, apart from their oldest substrata, as they are in the USA or in British countries. What makes the change from ordinary to interesting is simply the scale of events. "Go to equilibrium" is trivial in the simple pendulum because the balance is no longer a single point. However, when the system is more complex and when, for example, a country's economy fell backward from the war period to normal methods, the stable region is vast, and very interesting activities can occur in it [57].

To illustrate, up to the present, in Enna, the appearance of an original Islamic fabric has fundamentally changed. In the early 2000s, a new town (Southern Enna) formed a structural element, which dated back to the influence of the recent democratic government. This regular road network is in marked contrast to the narrow streets of the northern side of Enna (i.e., the core of the ancient town). The new town, directly in line with the old one and separated from it by a tabloid, constitutes a central business district (CBD) with many commercial activities, an athletics stadium, sports centers, cinemas, restaurants, a second Enna's weekly local town market and a number of connections via bus routes.

Here, the characteristics of the immediate residential area and the perception of these properties for the emergence of fear of crime are important. The starting point of this idea was the empirical finding that people frequently expressed fear of crime in residential areas, which were burdened with higher crime rates and in poor structural condition, and have made many households vulnerable [55]. The cause of fear of crime suggests that residents are exposed in areas with higher crime rates and, thus, have a higher risk of victimization.

In the 1970s, models started to think of a city as a dynamical system. Planners discovered that individuals' actions, as well as the opinions and initiatives of citizens' associations, become relevant to the purpose of land plans from a street, neighborhood, and town level. This is because of the perception of urban space-time change, ranging from the individual to different social, interest, and cultural groups: planning starts to become a process sensible to rapid variations of both individual moods and collective behaviors. In physics, this means to keep apart a privileged observer and account for a myriad of local observers, in a certain sense egalitarian, each one with its own measuring tool. "Only their composition can give place to a common vision. Composition will be always constituent, that is dynamic and never built once for all, also never static" [58] (p. 3). Would the observed values change if the shape and placing of the entity were manipulated? To give a first idea of the manipulation we applied to Enna's spatial state, we can start to imagine her map divided into 31 quadrants, each one representing the bulk of her grid environmental features, as is illustrated in Figure 2. 


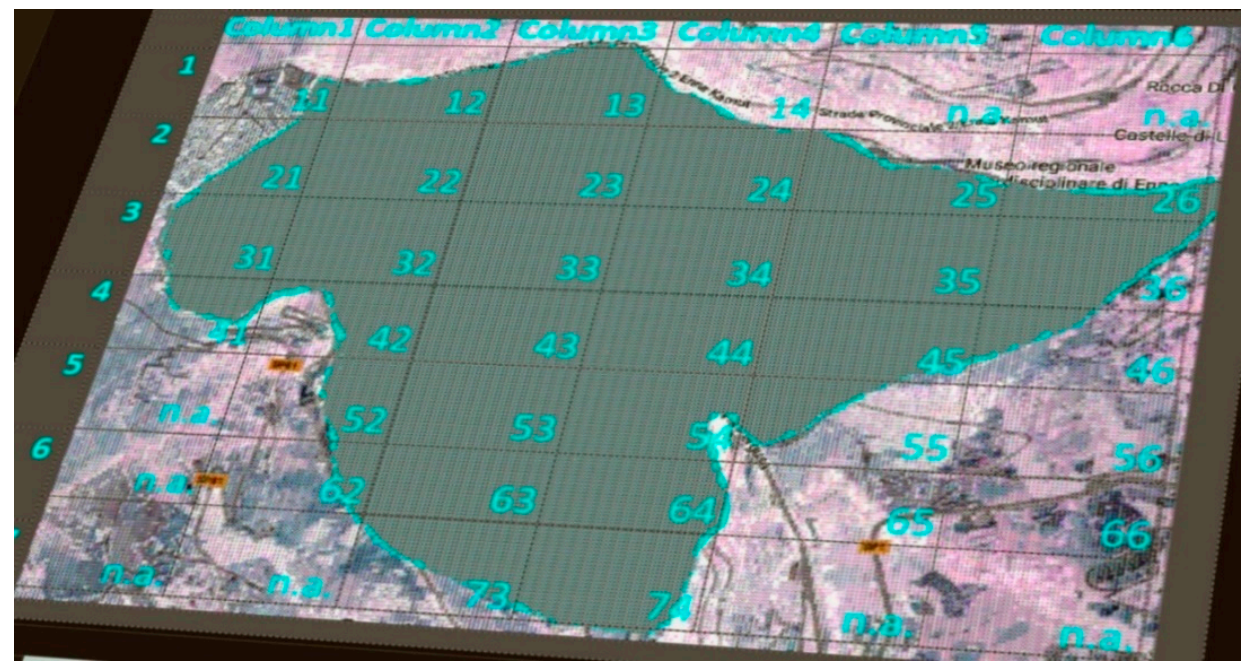

Figure 2. Enna and her matrix of 42 cells. Data have been collected only from 31 quadrants because of the shape of Enna's borders. The inclination of the figure is because Earth is not flat.

Apparently, there is no solution to the LTMAs' demarcation problem if we think a location is a determined square (at least, semi-squared) of $1.9 \mathrm{~km}^{2}$. How can it be demonstrated that an LTMA saturates other streets in many ways, such as car flows being constrained to deviate from ordinary traffic? If we try to compare, for instance, the rate of crime within an LTMA with that outside this area, our problem would then be to demarcate this LTMA from the rest of the town area. All over the town there will be shops and other amenities, but in the center there will be even more per square mile. However, a square mile is a unit far too large for this problem, so that per hectare $(100 \times 100 \mathrm{~m}$ $=10,000 \mathrm{~m}^{2}$ or roughly 2.5 acres) is a far better unit. Shops may form a kind of cluster on the map. Using the Voronoi diagram (getting areas for each shop), we could define an LTMA by considering that only shops in the area smaller than a limit that we might define arbitrarily as it might work out to be selective and therefore useful. After calculating the area of this selected LTMA, we might compare the rate of crime per hectare within these areas with those outside these areas.

For substantial new insight, we should relate the area with the number of people living in that area: dividing the number of people by the area in which they live, we would be able to calculate the ratio of crime per person in his/her living place. However, the LTMA is not only frequented by its own inhabitants, but also by people living outside this area. Therefore, we would need the number of people walking through the LTMA, and perhaps shopping there, in comparison with the people walking through the area and living in other parts of the town. It would be very difficult to obtain these numbers, but we should keep it in mind and perhaps hope that estimates exist.

Thus, models of bounded rationality, described above, as an opinion or a decision are reached (i.e., processes or mechanisms of heuristic approximation), rather than being merely the results of the decision and they describe the class of environments in which these heuristics will succeed or, on the contrary, fail. As explained by influential authors of the field, the fact of "being dispensed from optimization (as a model of cognitive processes) does not imply that the result of a non-optimizing strategy is poor" [59] (pp. 3-5). We opt therefore for models of "bounded rationality" [60] (pp. 653-655), which are exempt from the fiction of optimization, since in many real-world situations the optimization demands unrealistic assumptions about knowledge, time, attention, and other resources available to humans [61] (p. 85).

The dimensions, the structure, the function, and the diversity of systems must be ordered to be extended. In particular, it appears that a high diversity of interactions, processes, and functions, as well as the emergence of a self-regulation system with controlling feedback mechanisms, can account for safety. Even after systems theory allows for diversity in terms of high internal linking, it also claims for an increase in the "in-number" of potential system states. 
Dimensional reduction by constructing new features can be performed by applying some methods from statistics that construct new features to be used instead of the original features or by using some background knowledge for constructing new features usually to be used in addition to the original features. Feature construction that adds new features can be followed by feature subset selection." An attempt at considering new features of a potential system state is shown in Table 1.

Table 1. Attractors/detractors trajectory modeling.

\begin{tabular}{cccccc}
\hline Fixed Point & Limited Cycle & Through Trajectory \\
No external turbulence \\
in the circuit
\end{tabular} $\begin{gathered}\text { Movement is independent } \\
\text { in the circuit }\end{gathered}$

There are various types of attractors: (1) a fixed point, which occurs in a damped system without external turbulence. The system moves to this point, where the velocity is zero and the place is a point of rest. We call a point a stationary point, if for linear differential equations the trajectories that start in the catchment area of the attractor (fixed point) end in the attractor. The trajectories do not intersect. Another attractor is (2) the limited cycle, when the system moves independently from the initial point in time asymptotic to a closed curve in the phase space back. The system also becomes in the long run not at rest but is reached (after a certain settling time) always by the same cycle. For non-linear differential equations, stable trajectories end in limited cycles in multiple dimensions. The trajectories cannot intersect either. There is then (3) a through trajectory, which is a trajectory that is not closed. However, even in these attractors, the trajectory of different approaches returns to initial values. This form of chaos control is also called "delayed feedback control," (4) A back-loop is a reverse movement inward to complete the circuit. We say $(t-T)$ represents the difference between the above value before a round and the current time. $T$ can be developed out of the chaotic behavior, and this is a good approximation in that "time" in the trajectory almost returns to itself. Hence, we would name two mechanisms as important clues to the understanding of LTMA as self-organizing systems. One we may call the "fixed point from a fixed point" principle and the other one, the "limit cycle from limit cycle" principle. Both require the co-operation of a series of crime attractors/detractors who are part of the elements of our system.

\section{The "View" from the Local Town Market Area in Enna-Recognizing the Others}

The great essay of Donald Appleyard, The View from the Road [62], the title of which we eagerly recall in our paragraph, has suggested for the search for a physical environment could enhance sustainable developmental policies [63]. Markets have been traditionally placed where economic processes, such as the distribution of goods, tax collection, and price controls, are conducted as tools of the penetration of the central administration into the urban community texture. Thus, markets, on one hand, have been a crucial force for economic development and social cohesion. On the other, they have been attractive places for predatory crimes, because commuters find fragile open spaces in rundown 
areas where control is weaker than in closed surroundings. How is the right balance of residential, commercial, and tertiary functions reached? How is a continuous exchange of urban, social, and cultural features mixed safely, while coping with environmental factors and economic opportunities as well? Our shared conviction is that the high density, diversity, and proximity of facilities in LTMAs offer a good sustainable urban model, especially when spatial factors are balanced with their users' and inhabitants' acknowledged abilities.

Enna is a town in the middle of Sicily (its ancient name was Umbilicus, the belly button of the island), with a population of 29,387 inhabitants. The ancient part of the town is still built according to a transformed Arabic fabric, to which some greater thoroughfares have been added since the 1970s. The LTMA unit in Enna is located in Piazza Montesalvo, easily detectable on the southwestern side of the city and is extended to the center in the direction of the Armando Diaz Avenue. The intricate historic and traditional streets still prevail in the town center, which has a different building facet in comparison with the modern constructions erected in the new district of Enna Sant'Anna, also known as Southern Enna (dating back to 2000s) in close proximity to the Leonardo da Vinci Avenue [64] (pp. 14-16).

The Sant'Anna area, located in the lower part of the periphery of the ancient city (direction southeast) is an expansion district, thanks also to the recent growth of the University of Enna. Its population is around 12,000 inhabitants. Around an additional 10,000, composed mainly of student commuters, frequent Sant'Anna, especially during working days. The entire inner city is penetrated by residential areas-with a high concentration in the outskirts of the ancient Norman Castle. The residential areas have some social segregation: older residential areas with a wider (poorer) population at the edge of the ancient Norman Castle, densely built-up modern residential areas in the outskirts of the $\mathrm{CBD}$, and, thereafter, middle-class residential areas and residential suburbs. Once established, street alignments resisted short-term change, but changes over a span of centuries have been more common. In some cases, the principal streets were retained in roughly their original form; the other streets are highly irregular. The railroad, streetcar, and automobile city made a coherent system out of radial traffic arteries and girdle streets. A Google-driven 3D shot of Enna's LTMA and its surroundings is illustrated in Figure 3.

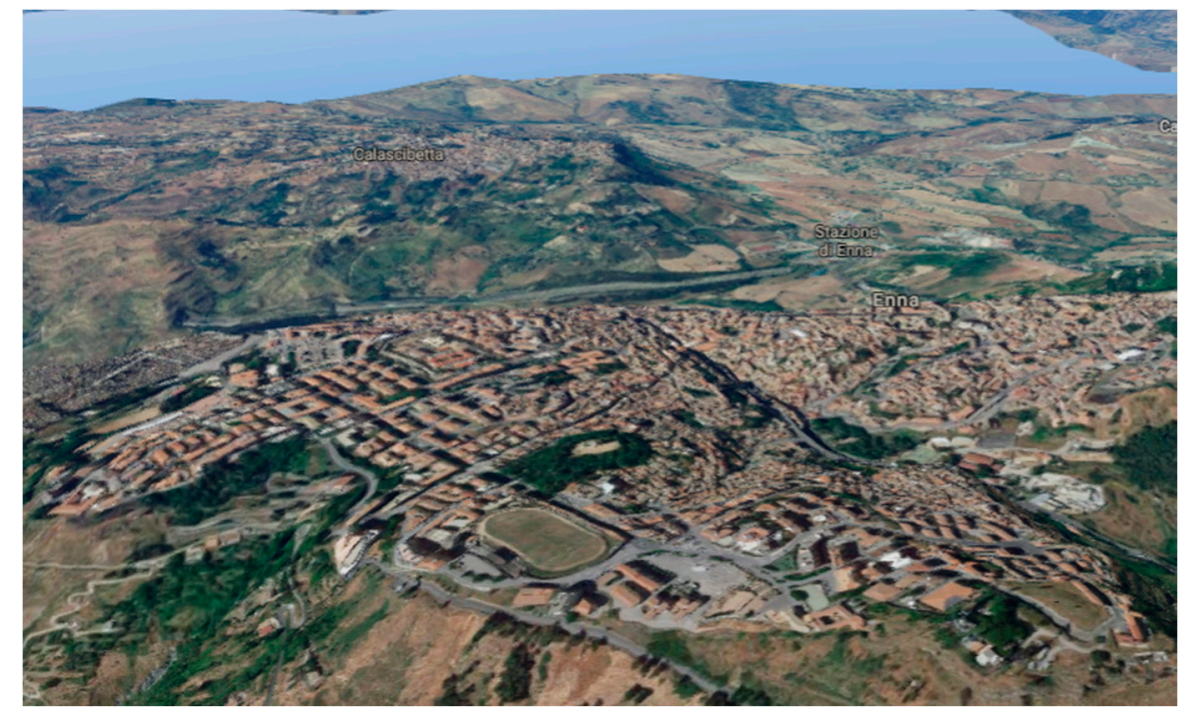

Figure 3. The LTMA in Enna and its surroundings from a 3D Google shot.

The city's economy is based primarily on the tertiary sector (in contrast to the entire province where the primary sector absorbs about $34 \%$ of production). However, apart from trade, Enna ranks in the middle in Sicily for national services, transport, and credit. The presence of industries is not appreciable, unlike the tourism sector with high perspectives (not adequately exploited) for the entire territory. In recent years, the city owns a newly built university development at the outskirts of the 
town. Local authorities and the media's role in advocacy have been instrumental in communicating and demonstrating pro-poor and environmentally sustainable alternatives. The municipality, in particular, has been a powerful and effective tool in raising the general awareness of the costs of environmental degradation and unsustainable management of natural resources. These costs run annually as high as $60 \%$ of the annual gross domestic product in local authorities' coverage of urban issues. Because a city's regeneration is deeply linked to its social structure, it will only work if it meets the needs of its inhabitants. Inquiries into LTMAs investigated funding opportunities, particularly for small private owners with low spending power and limited access to sophisticated financial support mechanisms.

\section{Findings: Enna in 31 Quadrants and Its Related Locations' State}

There are therefore behavioral traces, the physical features left behind resulting from human action or inaction. Two general clusters include evidence of a lack of caring, also called incivilities that include graffiti, litter, sites in disrepair, sites not cared for or closed and abandoned cars, and signs of investment and involvement, usually labeled "signs of attachment" or "territorial functioning" [65]. On one hand, we have enlisted places with well-defined routes, spaces, and entrances that provide for convenient movement without compromising security, places that are structured so that different uses do not cause conflict, places where all publicly accessible spaces are not overlooked, places that include necessary, well-designed security features, and places where the level of human activity is appropriate for the location and creates a reduced risk of crime and a sense of safety at all times. A list of sub-attractors helped us to better circumscribe the matter under analysis. Some locations (identified as "quadrants," see Figure 2 above) have therefore a spatial state slightly below the average in the town. A self-anchored scale with a range from 1 to 100 (ascending values) fulfills the evaluation of the state of locations (scores) in the 31 quadrants. There are no negative values; those below average indicate simply that the actual concentration of the above-mentioned factors lies below the lower end of the standard curve. This is especially due to the lack of resources in our times of economic austerity, as is illustrated in Figure 4.

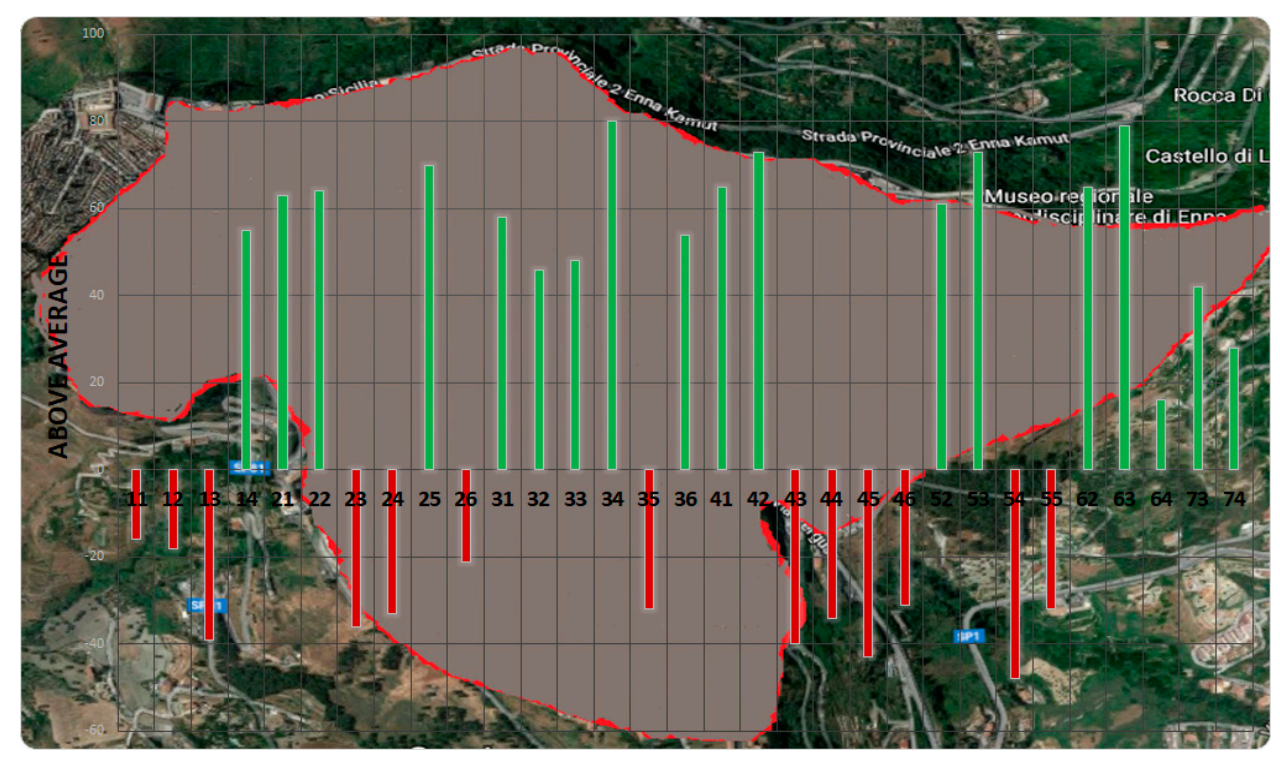

Figure 4. Spatial factors pinpointed starting from the LTMA to characterize the LS (locations' state) in all the town.

Accordingly, from a spatial perspective, the factors pinpointed starting from the LTMA have been the following:

- their distance to the closest major arteries;

- their distance to residential buildings; 
- their distance to public transportation facilities;

- their distance to the main facilities (e.g., schools, hospitals);

- their distance to institutional buildings (e.g., police, fire station);

- the actual state of buildings and streets in the area.

In the case of "access," we found that a percentage of pedestrian routes are poorly lit, indirect, and away from traffic streets. They include footpaths and alleyways that provide access to the rear of buildings. Streets and spaces are unwelcoming or underused by capable guardians. There are vacant buildings and dilapidated houses. Under- and unused buildings and spaces that have become vulnerable to crime are not remodeled or removed. We have therefore searched a reference frame $R F$ with the aim to specify the relationship between the observer and the phenomenon/phenomena under observation. Therefore, $N(\mathrm{x}, \mathrm{y}, \mathrm{t})$ is the $R F$ density at time $t$ at point $x, y$ on the landscape, $r$ is the per point growth rate, and $D$ is an arbitrary diffusion coefficient that indicates the rate of random movement across the landscape.

Let $x^{1}, x^{2}, \ldots, x^{\mathrm{n}}$ be $\mathrm{n}$ observations. Then the indexed $R F$ for the LTMA in Enna is

$$
R F=\mathrm{LS} \forall \mathrm{Q} \stackrel{\mathrm{m}}{=} \mathrm{VTMRw}
$$

where LS stands for "locations' state" scores in the 31 quadrants and VTMRw for the "variance to mean ratio" of all the windows are seeable based on the QCM (quadrant counts method) with the aim at weighing the LS scores in the quadrants. This is both because scores are self-anchored, which could cause a first bias in the $R F$, and because in our case quadrants have resulted rather overlapping since the smallness of the entire area under enquiry (see Figure 3). The distribution of quadrant counts shown in Figure 4 is therefore weighted by the number of windows (calculated as VTMR) are seeable through a Google-driven search, adding this way a dilatation/contraction of LS scores after we divided them by the VTMRw. Our scaling function related to the landscape's observations is in conclusion in contrast to general methods on spatial frames of reference and autocorrelation patterns based on characteristics of the ground, and other social variables are considered as forcing functions, since our model detects a subset in a contiguous landscape rather than multiple subsets across a fragmented landscape.

As a result, the $R F$ in the LTMA is characterized as follows:

$$
\frac{\mathrm{LS}}{\mathrm{VTMRw}} \approx \mathrm{D}
$$

where the dilatation/contraction of LS scores operated through the VTMRw is approximated by D coefficient, as shown in Table 2.

In the $R F$, safer and more sustainable quadrants are the 21st, 22nd, 25th, 31st, 42nd, and 54th, with a logarithmic regression at 0.996361997 . As a matter of fact, we have a plenty of unobserved variables because, if we could have fixed some commonalities (as we attempted with descriptive statistics) such as the state of locations (examples: buildings, settings, presence/absence of litter, private alarm systems, etc.) or other social variables such as population, income, education, and job activities of the area under enquiry, the area we want to sort out from our analysis is more interesting than simple sets of proximity locations starting from a centroid or point of interest (that is the physical place of the local town market, Piazza Europa). The likelihood of visualizing the LTMA somewhere else in the town is shown in Figure 5. 
Table 2. The reference frame in the LTMA.

\begin{tabular}{|c|c|c|c|c|c|c|}
\hline 31 Quadrants & LS Scores & Windows & Mean of Windows/31 & Variance & VTMRw & LS/VTMRw $\times 3000$ \\
\hline 11 & 16 & 235 & 8.61 & $25,625.79$ & 2975.64 & 16.13 \\
\hline 12 & 18 & 117 & 8.61 & 5873.99 & 682.08 & 79.17 \\
\hline 13 & 39 & 376 & 8.61 & $67,487.02$ & 7836.52 & 14.93 \\
\hline 14 & 55 & 186 & 8.61 & $15,733.28$ & 1826.93 & 90.32 \\
\hline 21 & 63 & 116 & 8.61 & 5766.11 & 669.55 & 282.28 \\
\hline 22 & 64 & 96 & 8.61 & 3818.34 & 443.38 & 433.04 \\
\hline 23 & 36 & 265 & 8.61 & $32,867.44$ & 3816.53 & 28.30 \\
\hline 24 & 33 & 100 & 8.61 & 4175.90 & 484.90 & 204.17 \\
\hline 25 & 70 & 100 & 8.61 & 4175.90 & 484.90 & 433.08 \\
\hline 26 & 21 & 98 & 8.61 & 3995.12 & 463.91 & 135.80 \\
\hline 31 & 58 & 95 & 8.61 & 3731.46 & 433.29 & 401.58 \\
\hline 32 & 46 & 269 & 8.61 & $33,900.99$ & 3936.55 & 35.06 \\
\hline 33 & 48 & 221 & 8.61 & $22,554.36$ & 2618.99 & 54.98 \\
\hline 34 & 80 & 379 & 8.61 & $68,593.69$ & 7965.02 & 30.13 \\
\hline 35 & 32 & 119 & 8.61 & 6092.77 & 707.49 & 135.69 \\
\hline 36 & 54 & 203 & 8.61 & $18,893.37$ & 2193.88 & 73.84 \\
\hline 41 & 65 & 334 & 8.61 & $52,938.72$ & 6147.19 & 31.72 \\
\hline 42 & 73 & 110 & 8.61 & 5139.78 & 596.83 & 366.94 \\
\hline 43 & 40 & 234 & 8.61 & $25,399.91$ & 2949.41 & 40.69 \\
\hline 44 & 34 & 476 & 8.61 & $109,225.84$ & $12,683.18$ & 8.04 \\
\hline 45 & 43 & 597 & 8.61 & $173,100.30$ & $20,100.22$ & 6.42 \\
\hline 46 & 31 & 688 & 8.61 & $230,784.12$ & $26,798.40$ & 3.47 \\
\hline 52 & 61 & 295 & 8.61 & $41,009.08$ & 4761.93 & 38.43 \\
\hline 53 & 73 & 310 & 8.61 & $45,417.40$ & 5273.82 & 41.53 \\
\hline 54 & 48 & 87 & 8.61 & 3072.35 & 356.76 & 403.64 \\
\hline 55 & 32 & 869 & 8.61 & $370,133.87$ & $42,979.54$ & 2.23 \\
\hline 62 & 65 & 430 & 8.61 & $88,783.98$ & $10,309.50$ & 18.91 \\
\hline 63 & 79 & 321 & 8.61 & $48,793.17$ & 5665.81 & 41.83 \\
\hline 64 & 16 & 96 & 8.61 & 3818.34 & 443.38 & 108.26 \\
\hline 73 & 42 & 112 & 8.61 & 5344.55 & 620.60 & 203.03 \\
\hline 74 & 28 & 342 & 8.61 & $55,573.83$ & 6453.17 & 13.02 \\
\hline
\end{tabular}

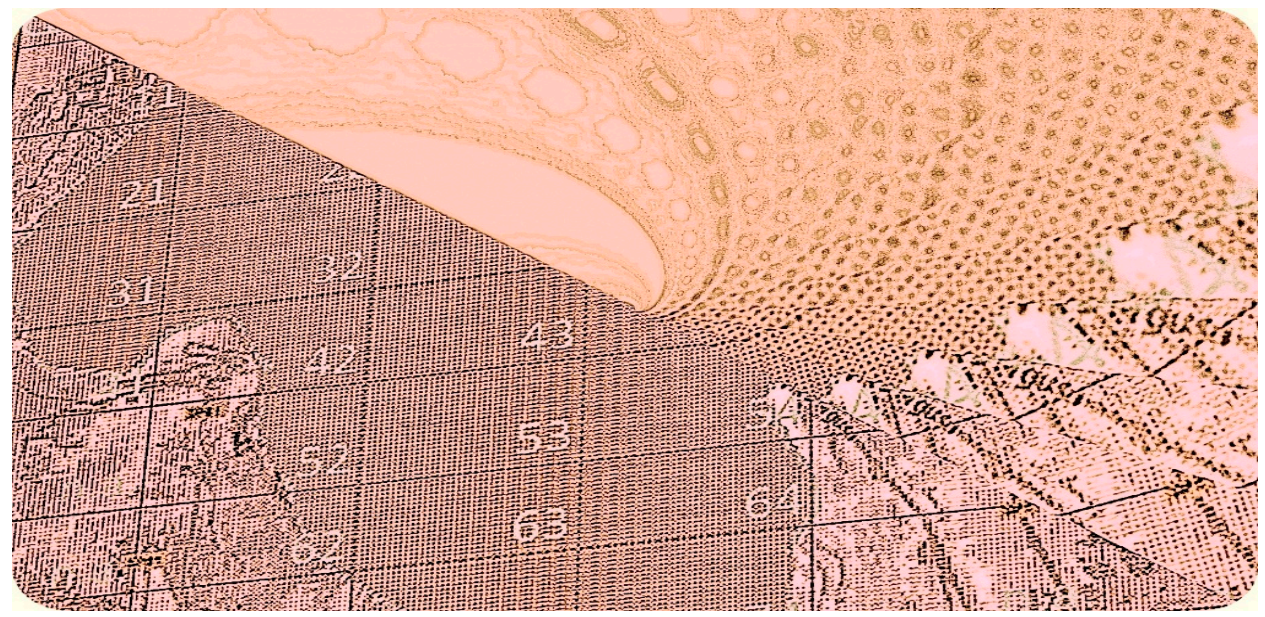

Figure 5. The LTMA can be spread along the town through a graphic cubic convolution. As in Figure 2, the LTMA is easily detectable in between Quadrants 52 and 53.

\section{Conclusions}

This paper has stressed the complexity of all the information that can explain the legibility of space: the environment's degree of self-organization, its human dimensions, the planning intervention, and so on, using the approach of the new research area of the psychology of sustainability and sustainable development. How is the right balance of residential, commercial, and tertiary functions reached? How is a continuous exchange of urban, social, and cultural features mixed safely while coping with environmental aspects and economic opportunities? 
Morphology has been studied as the first true joining between environmental and urban features, on the one hand, and social dynamics on the other. The salience of types moved from traditional patterns of development in the studied Sicilian urban contexts has revealed a special organizational form where local markets assume the cell element for territoriality, monitoring, and self-security feelings. We have analyzed the impact of many different sets of ideal typical geographical investigations on the creation of revitalization planning strategies.

This article furthermore aims to constitute a precedent for similar inquiries and underscores how physical and spatial variables on the built environment account for the occurrence of crime much more than other potential human sources of conflict in the city. This should be sufficient for us to take care of our living spaces and to preserve regeneration and beautification, despite the financial restraints of the present.

Finally, the following three principles are believed to be critical in achieving profound quality or safety in the built environment:

1. Deep surveying of the specific fabric of a pre-existing urban space. The application of this principle helps us ensure that qualities indeed originate from existing patterns in a given project-both traditional and modern ones-without falling into the trap of imitating traditional aspects without a corresponding social and cultural development.

2. Preservation of symbolic planning. The application of these two closely related principles ( 1 and 2 ) helps ensure that patterns and projects find their corresponding reality of space, geometry, color, materials, and construction systems; in particular, symbolic meanings are intersubjectively shared by specific cultural groups.

3. Enhancement of community participation in planning processes. This process helps to ensure that changes and fine adaptations can occur, especially during the planning period, without endangering the basic traditional features of an urban community.

The interpersonal relations in which we deal with the "actors in the situation," as well as the interrelation of the social bonds, replace our sociometric networks [66]. This interaction in which everyone is contemplated with the eyes of others, had been written in 1914, in his Einladung zu einer Begegnung: "A march to two: the eye in front of the eye, the mouth in front of the mouth. And if you're with me, I will tear your eyes from their inside and will put them in the place of mine, and you tore me from my own, and then I look at you and you will look at me with mine." [67]. In this role-playing game that Moreno recommends, the subject can fully exercise their freedom, while, where it does not come to manifest itself in "taking the leading role," it appears in its pure state in the "creation of the role," combining spontaneity and creativity, which is the socio-metric system's cornerstones.

Author Contributions: Conceptualization: R.F. and S.C.; methodology: R.F., S.C., and G.F.; formal analysis: R.F., S.C., and G.F.; investigation: R.F.; resources: R.F., S.C., G.F., and J.L.; data curation: R.F., S.C., and G.F.; writing-original draft preparation: R.F., S.C., and G.F.; writing-review and editing: R.F., S.C., and G.F.; visualization: R.F., S.C., and G.F.; supervision: R.F., S.C., G.F., and J.L.

Acknowledgments: One of the authors at the University of Verona is thanked for her believing in the general project as well as for her psychological support in all stages of its preparation and formalization. Special thanks go to G. Salustri, a physicist at the University of Bologna, and to Arch. V. Scavone, a researcher and urbanist at the DARCH Dept. of the University of Palermo. Jeff Crowe, editor in Skegness, Lincolnshire, UK, has been amazingly helpful in polishing the language and in summarizing the formalities useful to the first draft of the paper.

Conflicts of Interest: The authors declare no conflict of interest.

\section{References}

1. Lin, J.; Mele, C. The Urban Sociology Reader; Routledge: Abingdon, UK, 2013.

2. Batty, S.; Davoudi, S.; Layard, A. (Eds.) Planning for a Sustainable Future; Taylor \& Francis: New York, NY, USA, 2008.

3. Van den Berg, L.; Pol, P.M.J.; Mingardo, G.; Speller, C.J.M. (Eds.) The Safe City: Safety and Urban Development in European Cities; Ashgate: Aldershot, UK, 2006. 
4. Lee, A.C.; Jordan, H.C.; Horsley, J. Value of urban green spaces in promoting healthy living and wellbeing: Prospects for planning. Risk Manag. Healthc. Policy. 2015, 8, 131-137. [CrossRef]

5. Shaw, C.R.; McKay, H.D. Criminological Theory. Past to Present; Cullen, F.T., Agnew, R., Eds.; Oxford University Press: Oxford, UK, 2011.

6. Barthel, M.; Fava, J.A.; Harnanan, C.A.; Strothmann, P.; Khan, S.; Miller, S. Hotspots Analysis: Providing the Focus for Action. In Life Cycle Management. LCA Compendium-The Complete World of Life Cycle Assessment; Sonnemann, G., Margni, M., Eds.; Springer: Dordrecht, The Netherlands, 2015.

7. Kao, L.-S.; Chiu, Y.-H.; Tsai, C.-Y. An Evaluation Study of Urban Development Strategy Based on of Extreme Climate Conditions. Sustainability 2017, 9, 284. [CrossRef]

8. Brunsdon, C.; Corcoran, J.; Higgs, G. Visualising space and time in crime patterns: A comparison of methods. Comput. Environ. Urban Syst. 2007, 31, 52-75. [CrossRef]

9. Sassen, S. Whose City Is It? Globalization and the Formation of New Claims. Available online: https:/ / read.dukeupress.edu/public-culture/article-abstract/8/2/205/32197/Whose-City-Is-It-Globalizationand-the-Formation?redirectedFrom=fulltext (accessed on 17 January 2019).

10. Le Galès, P. European Cities: Social Conflicts and Governance: Social Conflicts and Governance; Oxford University Press: Oxford, UK, 2004.

11. Kim, D.; Lim, U. Social Enterprise as a Catalyst for Sustainable Local and Regional Development. Sustainability 2017, 9, 1427. [CrossRef]

12. Robert, J.; Bursik, Jr.; Grasmick, H.G. Neighborhoods \& Crime. The Dimensions of Effective Community Control; Lexington Books: Lanham, MD, USA, 2001.

13. Foster, S.; Knuiman, M.; Wood, L.; Giles-Corti, B. Suburban neighbourhood design: Associations with fear of crime versus perceived crime risk. J. Environ. Psychol. 2013, 36, 112-117. [CrossRef]

14. Daclon, C.M. Geopolitica Dell'ambiente. Sostenibilità, Conflitti e Cambiamenti Globali; Franco Angeli: Milano, Italy, 2008.

15. Sassen, S. The City: Its Return as a Lens for Social Theory. In The Sage Handbook of Sociology; Calhoun, C., Rojek, C., Turner, B., Eds.; Sage Publications Ltd.: London, UK, 2005; p. 459.

16. Baran, P.K.; Smith, W.R.; Toker, U. The Space Syntax and Crime: Evidence from a Suburban Community. In Proceedings of the 6th International Space Syntax Symposium, Istanbul, Turkey, 2007. Available online: https:/ / pdfs.semanticscholar.org/cede/770002c2eeccd3453969a6978a6a28cb006b.pdf (accessed on 18 December 2018).

17. Chavis, D.M.; Wandersman, A. Sense of community in the urban environment: A catalyst for participation and community development. Am. J. Commun. Psychol. 1990, 18. [CrossRef]

18. Jacobs, J. The Death and Life of Great American Cities; Random House: New York, NY, USA, 1961.

19. Habermas, J. Theory and Practice; Beacon Press: Boston, MA, USA, 1973.

20. Teisman, G.R. Complexe Besluitvorming: Een Pluricentrisch Perspectief op Besluitvorming over Ruimtelijke Investeringen; Elsevier: Rotterdam, The Netherlands, 1992.

21. Van Gunsteren, H.R. A Critique of the Rational-Central-Rule Approach in Public Affairs; John Wiley: London, UK, 1976.

22. Ellickson, R.C. Controlling Chronic Misconduct in City Spaces: Of Panhandlers, Skid Rows, and Public-Space Zoning. Faculty Scholarship Series, Paper 408. 1996. Available online: http://digitalcommons.law.yale.edu/ fss_papers / 408 (accessed on 9 January 2019).

23. Newman, O. Architectural Design for Crime Prevention; Institute of Planning and Housing: New York, NY, USA, 1971.

24. Mosher, C.J.; Miethe, T.D.; Hart, T.C. The Mismeasure of Crime; SAGE Publications Ltd.: London, UK, $2011 ;$ p. 5.

25. Shapland, J.; Vagg, J. Quantitative Review. In Fear of Crime. Audit of the literature and Community Programs; Tulloch, J., Ed.; Commonwealth of Australia, May 1998; Volume 1, p. 25. Available online: http://www. criminologyresearchcouncil.gov.au/reports/1998-foc1.pdf (accessed on 16 January 2019).

26. Gans, H. The Urban Villagers; Free Press of Glencoe: New York, NY, USA, 1962.

27. Power, A.; Houghton, J. Jigsaw Cities: Big Places, Small Spaces; Policy Press: Bristol, UK, 2007.

28. Dias Lay, M.C.; Reis, A.; Dreux, V.; Becker, D.; Ambrosini, V. Spatial Configuration, Spatial Behaviour and Spatial Cognition: Syntactic and Perceptual Analysis of the Market Station Area in Porto Alegre. EDRA36. 2005, pp. 129-136. Available online: http:/ / www.edra.org/sites/default/files/publications/EDRA36-Lay_ 0.pdf (accessed on 18 December 2018). 
29. Sampson, R.J.; Raudenbush, S.W. Systematic social observation of public spaces: A new look at disorder in urban neighborhoods. Am. J. Sociol. 1999, 105, 603-651. [CrossRef]

30. Wilson, J.; Kelling, G. Broken windows: The police and neighbourhood safety. Atl. Mon. 1982, 249, $29-38$.

31. Welwei, K.-W. La Polis Greca; [The Greek polis]; il Mulino: Bologna, Italy, 1988; p. 9.

32. Deodatis, G.; Ellingwood, B.R.; Frangopol, D.M. Safety, Reliability, Risk and Life-Cycle Performance of Structures E Infrastructures; Taylor \& Francis Group: London, UK, 2013.

33. Anderson, J.M.; MacDonald, J.M.; Bluthenthal, R.; Ashwood, J.S. Reducing Crime by Shaping the Built Environment with Zoning: An Empirical Study of Los Angeles. Univ. PA Law Rev. 2013, 699, 701. [CrossRef]

34. Bottoms, A.E.; Wiles, P. Environmental Criminology. In The Oxford Handbook of Criminology; Maguire, M., Moran, R., Reiner, R., Eds.; Clarendon Press: Oxford, UK, 1997; p. 633.

35. Cohen, LE.; Felson, M. Social Change and Crime Rate Trends: A Routine Activity Approach. Am. Sociol. Rev. 1979, 44, 588-608. [CrossRef]

36. Brantingham, P.J.; Brantingham, P.L. Patterns in Crime; MacMillan: New York, NY, USA, 1984.

37. Buck, J.; Hakim, S.; Rengert, G.F. Burglar alarms and the choice behavior of burglars: A suburban phenomenon. J. Crim. Just. 1993, 21, 497-507. [CrossRef]

38. Lambert, R.D. Routine Activity and Rational Choice; Routledge: Abingdon, UK, 2017; Volume 5.

39. Gillingwater, D.; Ison, S. Planning for sustainable environmental futures. In Handbook of Transport and the Environment; Hensher, D.A., Button, K.J., Eds.; Elsevier: Oxford, UK, 2003; p. 561.

40. Picone, M. Essere zen oggi. In Città Nell'emergenza. Progettare e Costruire tra Gibellina e lo Zen; Badami, A., Picone, M., Schilleci, F., Eds.; Palumbo \& C. Editore: Palermo, Italy, 2008; pp. 245-255.

41. D'Urso, A. Urban Settlement Process In Sicily: From History To The Contemporary Period. Review of Historical Geography and Toponomastics. 2011, volume VI, 11-12. pp. 15-29. Available online: http:/ / www.geografie. uvt.ro/old/en/research/publications/rhgt/articles/rhgtpaper2011vol06no1112_07urso.pdf (accessed on 16 January 2019).

42. Renda, M. I Nuovi Insediamenti nel '600 Siciliano. In Città nuove di Sicilia XV-XVI Secolo; [New Town of Sicily in the XV and XVI centuries]; Giuffré, M., Ed.; Vittorietti Editore: Palermo, Italy, 1979; pp. 31-41.

43. Di Fabio, A. The psychology of sustainability and sustainable development for well-being in organizations. Organ. Psychol. 2017, 8, 1534. [CrossRef] [PubMed]

44. Di Fabio, A. Positive Healthy Organizations: Promoting well-being, meaningfulness, and sustainability in organizations. Organ. Psychol. 2017, 8, 1938. [CrossRef] [PubMed]

45. Leone, N.G. Elementi Della Città e Dell'urbanistica; Palumbo editore: Palermo, Italy, 2004.

46. Committee on Spatial Development of the European Commission. European Spatial Development Perspective: Towards Balanced and Sustainable Development of the Territory of the EU; Office for Official Publications of the European Communities: Luxembourg, 1999. Available online: https:/ / ec.europa.eu/regional_policy/ sources/docoffic/official/reports/pdf/sum_en.pdf (accessed on 16 January 2019).

47. Sassen, S. The City: Between Topographic Representation and Spatialized Power Projects. Art J. 2001, 60, 13. [CrossRef]

48. Anttiroiko, A.-V. Cities-as-a-Platform: The Rise of Participatory Innovation Platforms in Finnish Cities. Sustainability 2016, 8, 922. [CrossRef]

49. Seung Lee, J.; Park, S.; Jung, S. Effect of Crime Prevention through Environmental Design (CPTED) Measures on Active Living and Fear of Crime. Sustainability 2016, 8, 872. [CrossRef]

50. Clarke, R.V. Improving Street Lighting to Reduce Crime in Residential Areas. Response Guide No. 8. 2008. Available online: http:/ / www.popcenter.org/Responses/street_lighting/print/ (accessed on 16 December 2018).

51. Farrington, D.P.; Welsh, B.C. Improved street lighting and crime prevention. Just. Q. 2002, 19, 313-342. [CrossRef]

52. Zelinka, A.; Brennan, D. Safescape: Creating Safer, More Livable Communities Through Planning And Design; Planners Press, American Planning Association: Chicago, IL, USA, 2001; pp. 10-11.

53. Roberts, P. Social Innovation, Spatial Transformation and Sustainable Communities: Liverpool and the 'Eldonians'. In The Challenge of Social Innovation in Urban Revitalization; Drewe, P., Klein, J.-L., Hulsbergen, E., Eds.; Techne Press: Amsterdam, The Netherlands, 2008; pp. 117-133.

54. Conklin, J.E. Dimensions of community response to the crime problem. Soc. Probl. 1971, 18, 373-385. [CrossRef]

55. Hale, C. Fear of Crime: A Review of the Literature. Int. Rev. Victimol. 1996, 4, 79-150. [CrossRef] 
56. Crowe, T.D.; Zahm, D.L. Crime Prevention Through Environmental Design. Land Development. 1994. Available online: https://popcenter.asu.edu/sites/default/files/Responses/closing_streets/PDFs/Crowe_ Zahm_1994.pdf (accessed on 16 December 2018).

57. Ashby, R.W. An Introduction to Cybernetics; Chapman and Hall Ltd.: London, UK, 1956.

58. Giorgini, B.; Melchiorre, G. La Fisica della Città. Mobilis: Un Laboratorio Virtuale per una Mobilità Sostenibile; [Physics of cities. Mobilis: A virtual laboratory for a sustainable mobility]; Bologna, Italy, 2004; pp. 1-8. Available online: http:/ / www.physycom.unibo.it/giorgini/sapere.pdf (accessed on 16 January 2019).

59. Selten, R. What is Bounded Rationality? Paper prepared for the Dahlem Conference, May 1999; SFB Discussion Paper B-454. pp. 3-5. Available online: https://pdfs.semanticscholar.org/8237/ d1a44256daddab131078bd09d622216c90d8.pdf (accessed on 16 January 2019).

60. Gigererzer, G.; Goldstein, D.G. Reasoning the Fast and Frugal Way: Models of Bounded Rationality. Psychol. Rev. 1996, 103, 653-655.

61. Saunders, C. Subspace, Latent Structure and Feature Selection: Statistical and Optimization Perspectives Workshop; SL SFS: Bohinj, Slovenia, 23-25 February 2005; p. 85.

62. Appleyard, D. The View from the Road; MIT Press: Cambridge, UK, 1964.

63. Di Fabio, A.; Rosen, M.A. Opening the Black Box of Psychological Processes in the Science of Sustainable Development: A New Frontier. Eur. J. Sustain. Dev. Res. 2018, 2, 47. [CrossRef]

64. Severino, CG. Enna. La Città al Centro; [Enna. The city to the centre]; Gangemi Editore: Palermo, Italy, 1996; pp. 14-16.

65. Taylor, R.B.; Gottfredson, S.D.; Brower, S. Block Crime and Fear: Defensible Space, Local Social Ties and Territorial Functioning. J. Res. Crime Delinq. 1984, 21, 303-331. [CrossRef]

66. Moreno, J. Who Shall Survive? A New Approach to the Problem of Human Interrelations; Nervous and Mental Disease Publishing Co.: Washington, DC, USA, 1934.

67. Moreno, J. Einladung zu Einer Begegnung; Anzengruber Verlag: Wien, Austria, 1914.

(C) 2019 by the authors. Licensee MDPI, Basel, Switzerland. This article is an open access article distributed under the terms and conditions of the Creative Commons Attribution (CC BY) license (http://creativecommons.org/licenses/by/4.0/). 